\section{Use and abuse of amphetamine-type stimulants in the United States of America}

\author{
G. Cajetan Luna ${ }^{1}$
}

Key words: Drug abuse, amphetamines, United States of America.

\footnotetext{
AIDS Resources, Information, and Services of Santa Clara County, 380 N. First Street, Suite 200, San Jose, California 95112-4050, United States of America. Telephone: (408) 293-2747; fax: 408-293-0341; e-mail: cajetan@aris.org
}

In recent years the United States of America has experienced economic growth, low unemployment, low inflation, and technological advances. However, coexisting with these favorable conditions are underlying and underaddressed social inequalities that may have an impact on patterns of use and abuse of substances, including amphetamine-type stimulants (ATSs). For example, since 1975 most of the increase in national income has benefited people who are at the top $20 \%$ of the income range. There are disparities between those who do have and those who do not have the skills needed to thrive in a technologically dependent society, and the gap may be widening. New patterns of substance abuse being seen in the United States may in part be explained by the increasing competition to survive financially and interpersonally, the need that those failing to adapt to rapid technological change have to escape psychologically and existentially, and the desire of the socially alienated and disenfranchised to self-medicate with ATSs and at least temporarily avoid social and economical inequities.

According to the 1998 National Household Survey on Drug Abuse, an estimated 13.6 million Americans were users of illicit drugs (1). This number is less than the 13.9 million estimated for 1997, and by comparison less than the highest level, in 1979, when the estimate was 25 million. With respect to stimulants in particular, the overall level of usage has remained constant, but increases have been observed in specific high-risk populations, who need focused outreach and intervention efforts. This article will focus on ATSs in the United States, including relevant demographic and cultural dimensions of their use and abuse, and suggested directions for future ATS research and program development.

\section{ATS USE AND ABUSE IN THE UNITED STATES}

\section{The history of ATS use and control}

For many decades in the United States punitive actions have been taken against persons seeking substance-induced altered states of consciousness. These have ranged from the alcohol "prohibition" in the 1920s to the "drug bust" arrests 
of users in the psychedelic 1960s to the "war on drugs" campaign of the 1980s. There are now more persons incarcerated in the United States for drugrelated "crimes" than in any other country in the world. In 1997, 19\% of prisoners in state facilities and $16 \%$ of those in Federal penitentiaries reported they had committed their current offense in order to obtain money for drugs (2).

The desire to expand reality, to lower inhibitions, or to soften the consequences of unpleasant life circumstances has remained consistent, but the popular or preferred substances employed for those effects have varied with succeeding generations. Tobacco, alcohol, and marijuana are still the substances most widely abused by American children and adolescents (3).

Various amphetamine compounds have been abused in the United States for over 90 years (4). Amphetamines comprise a large class of stimulants and include ones produced and used both legally and illegally. When used appropriately, amphetamines can help reduce attention deficit hyperactivity disorder, the most common psychiatric problem reported among children in the United States. While widely prescribed for this disorder, amphetamines are also frequently diverted from prescription to recreational use. Amphetamines can elevate mood, promote feelings of euphoria, decrease inhibitions, increase energy and alertness, reduce the need for sleep, and suppress appetite (5). Users have reported enhanced cognitive and physical abilities, as well as increased libido (6).

Among the legally produced pharmaceuticals that are sometimes diverted to recreational use are methylphenidate (Ritalin) and phenmetrazine (Preludin). Illegally produced "street" ATS drugs include amphetamine (in slang called "black beauties," "white bennies," "speed") and such related compounds as dextroamphetamine ("dexies," "beans"), methamphetamine ("crank," "crystal," "meth"; also "speed"), methylenedioxymethamphetamine (MDMA, known as "ecstasy," "XTC," and "E"), and methcathinone ("cat," "bathtub speed," "goob"). These illicit drugs can be consumed in different modes, including being taken orally, injected, smoked, or snorted (inhaled into the nose). Injecting or smoking facilitates an immediate, intense sensation, called a "rush."

Since the early 1900s, amphetamine users and abusers have tended to be white males, persons living in the western United States, and individuals working in blue-collar, transportation, or servicerelated occupations. Other regular users and abusers of amphetamine-type stimulants have included athletes, college students, and those desiring quick weight loss. Although a prescription was required for the medical use of amphetamines in the United
States during the 1950s, large drug companies sold quantities of the drugs to bogus companies in care of post office boxes. Known as "pep pills," the drugs were used for nonmedical purposes by many World War II veterans. In the 1960s, some doctors in San Francisco began prescribing amphetamine injections for treatment of heroin addiction. Other physicians, known as "script writers," would, for the cost of an office visit, write prescriptions for amphetamines.

ATSs came under new, stricter controls with the passage of the Federal Drug Abuse Control Substances Act of 1965. Subsequently, that legislation was consolidated with other laws into the Controlled Substances Act of 1970. That 1970 legislation regulates the manufacture and distribution of ATSs and other stimulants, as well as of narcotics, hallucinogens, steroids, and chemicals used in the illicit production of controlled substances.

Further limitations on ATSs came with the Federal Domestic Chemical Diversion Act of 1993, which controls the diversion of ephedrine and other legally obtainable chemicals for use in the illicit production of controlled substances, including methamphetamine and methcathinone. Ephedrine is present in many easily obtainable, legal products, including ones used to control coughs, asthma, and allergies. Ephedrine occurs naturally in ma huang (Ephedra equisetina), and it is a bronchodilator and a common ingredient in products for weight loss. Ephedrine is structurally related to methamphetamine, but ephedrine's central nervous system actions are less potent. In 1995 the United States Food and Drug Administration (FDA) mandated that producers of bronchodilator drugs remove from them ephedrine and related ingredients, including ephedrine hydrochloride, ephedrine sulfate, and racephedrine hydrochloride. The FDA acted in response to a request from United States Justice Department's Drug Enforcement Agency (DEA) to restrict over-the-counter (OTC) use of bronchodilator drugs because of their use as the primary precursor in the illicit synthesis of methamphetamine and methcathinone.

A number of states in the United States have taken actions of their own to control products containing ephedrine. Of the 50 states in the country, at least 14 of them have switched products containing ephedrine to prescription-only status. Several states have introduced legislation that would tighten controls on ephedrine, phenylpropanolamine, and other precursor chemicals used to illegally produce ATSs. The attorney general of the state of Arizona plans legislation specifically limiting individual purchases of most ephedrinecontaining OTC cold and allergy medications (7). That legislation would limit purchases to 20 pack- 
ages in a 24-hour period. A major national chain of retail stores already restricts the number of packages of these products that their customers can buy. If a customer exceeds the limit, the cash register automatically shuts down.

\section{ATS usage patterns and populations at risk}

ATS abuse occurs among a wide variety of populations in the United States. Such users are predominately white middle-class teenagers and young adults. Amphetamines are also frequently used, in various forms, by male and female commercial sex workers (both street-based and through organized call services), transgendered people, habitués of gay and straight nightclubs, and college students. Frequent users also include rural migrant farm workers, homeless persons, men who have sex with men, and members of motorcycle groups $(8$, 9). ATS use is increasing among women, AfricanAmericans, Hispanics, and Asians in the United States.

A number of problems result from ATS abuse. These include increased health care expenditures, premature deaths from overdosing, impaired productivity due to chronic use, motor vehicle accidents, and violence and crime both as the result of ATS use and in order to obtain money to continue or maintain use.

Data from hospital emergency rooms are limited (9), but another source reports that between 1997 and 1998 methamphetamine-related deaths declined in the cities of Philadelphia, San Diego, Seattle, and Honolulu, but they rose in the urban areas of Minneapolis/St. Paul and Phoenix (10).

In recent years, illegal, clandestine laboratories to produce methamphetamine have become commonplace throughout the United States, especially in remote and rural areas. These laboratories generate toxic and hazardous environmental wastes, in addition to producing methamphetamine.

There are numerous national and thousands of local nongovernmental community-based organizations addressing ATS issues throughout the United States. Such self-help groups as Narcotics Anonymous and Cocaine Anonymous operate in most major cites $(11,12)$. ATS issues are usually addressed within existing substance abuse treatment programs serving a full range of abuse issues, or at treatment programs located within community hospitals.

Ethnographic studies have found two drugs to be endemic to the gay male club and circuit party scenes $(7-9,10,13,14)$. One is methamphetamine, and the other is the "designer" drug methylene- dioxymethamphetamine (MDMA), which is commonly known as "ecstasy." Ecstasy causes mescaline-like psychedelic effects. First used in the 1980s, ecstasy is found in many major cities and suburban areas of the United States. Relatively inexpensive, the drug is popular among the young. Continuous "techno" music, rampant ecstasy use, and a "utopian" togetherness fuel urban dance scenes, including energetic all-night "raves" that feature euphoric marathon dancing and chemically induced "soul expansion." Clandestine by nature, raves are optimally held in vast open-air environments, with the location announced by promoters through flyers, secret phone numbers, and Internet mailing lists. And while raves have declined more recently in some urban areas, they have grown in popularity in other sections of the United States, including even rural regions (15).

Overlapping high-risk populations, which are at times part of the club and rave scenes, include highly mobile and disenfranchised street youth present in many cities in the United States. Characterized by multiple body piercings, tattoos, and unstable housing arrangements, these youth are frequently avid users of crystal methamphetamine, either injected or smoked. Male and female sex workers were found to be heavy users of methamphetamine in San Francisco (14). A strong interrelationship exists between sex work and substance abuse, largely as the result of the accompanying lifestyles and behavioral characteristics. Many sex workers live an accelerated lifestyle, using alcohol and drugs that impair judgement. Substance abuse is encouraged by irregular and late hours, multiple and sometimes disagreeable customers, and the need to relax inhibitions in order to participate in undesirable sexual activities (16). Among gay and bisexual male sex workers there is a particular preference for injecting crystal methamphetamine since injecting methamphetamine initially heightens sexual arousal. Dancing, drugs, and sex are common features of weekend gay "white parties" (white underwear or pajamas are the required apparel). The West Coast cities where these parties are held include San Francisco, Los Angeles, and Palm Springs. A ritualistic character to needle sharing among gay male partners exists when using "speed" and is sometimes an integral part of relationship building, establishing trust, and lovemaking (14). Health officials report that in the South Beach section of Miami ecstasy tablets sold at local raves and clubs are mixed with other drugs in combinations known as "rolls," which produce seesaw stimulant and depressant effects.

According to the DEA, most methamphetamine comes from the West Coast, although illegal 
production labs and manufacturing sites have been identified in most states of the country. The $\mathrm{Na}-$ tional Institute on Drug Abuse (NIDA) of the United States estimated that in 1996 there were some 1.46 million intravenous drug users (IVDUs) in the country (17). This number is considered an underestimate, as it does not include the more than 1 million incarcerated people or 650000 homeless people who are IVDUs (18). Most IVDUs are found on the East Coast of the United States, with the largest concentration in New York City (estimated to be upwards of 250000 persons). While methamphetamine is frequently injected, specific rates for that mode of ATS use are unavailable.

Young males predominate in mortality and treatment indicators for methamphetamine abuse $(7,9,10)$. Admissions to stimulant treatment programs are more often among persons 35 years of age or younger, in every city where information is available. In December 1998 the High School Senior Monitoring the Future Survey found that $10.1 \%$ of high school youths had used stimulants within the preceding 12 months, with the usage percentages only being higher for alcohol (74.3\%) and marijuana $(37.5 \%)$. Just over $60 \%$ of the youths surveyed reported that they could obtain amphetamines easily or very easily. Many of the youths interviewed who used illicit substances did not consider ATSs to be as harmful or addictive as cocaine or heroin. In recent years methamphetamine use has increased in the cities of San Francisco and Seattle, but has stabilized or gone down in the cities of San Diego and Los Angeles.

Increased methamphetamine availability and abuse in diverse areas of the United States have prompted concern about its spread outside of the areas of endemic use on the West Coast $(7,9,10)$. Methamphetamine is an easily manufactured stimulant. In 1998 the DEA identified 454 clandestine methamphetamine laboratories in just the three midwestern states of Missouri, Kansas, and Nebraska. Many of these labs use precursor techniques involving ephedrine or antihistamines, making methamphetamine easy to synthesize and requiring little or no previous knowledge of drug chemistry.

Methamphetamine is typically inhaled or put into liquids, and sporadic injection use has been reported $(7,9,10)$. Phenmetrazine (Preludin) is available in the North Side section of Chicago, where users inject the drug. Ecstasy use was reported most often among young adults and adolescents at dance clubs, raves, and rock concerts in Atlanta, Miami, St. Louis, Seattle, and in Texas cities. The DEA has reported that in the city of Phoenix, Arizona, there is an emerging production technique whereby road flares containing red phosphorous are ground up and used in methamphetamine production (7). Other easily obtainable substances used in the illegal preparation of methamphetamine can include iodine crystals, ephedrine, dextromethorphan, pseudoephedrine, and pool acid (10).

In the United States illegal ATSs are versatile drugs, being taken orally, snorted, injected, or smoked. The route of administration varies from city to city and from region to region within the country. In addition, products called "look alikes" or "act alikes" are being manufactured legally to resemble illegal amphetamines and to mimic their effects. These products usually contain varying amounts of ephedrine, caffeine, and phenylpropanolamine.

Another ATS, recrystallized methamphetamine hydrochloride ("ice"), is very potent. It usually takes the form of clear crystallized chunks. It induces a profound sense of euphoria by blocking the reuptake and stimulating the release of dopamine and noradrenaline in the central nervous system. Its use is typically followed by prolonged depression and fatigue. When smoked, its effects can last up to 24 hours.

In San Francisco, methamphetamine is put into coffee in what is termed "biker's coffee." This use is reported to be popular among young urban professionals who want the drug's energizing and appetite suppressant effects but without having to snort or inject it. Some methamphetamine users break off the tops of light bulbs, put the drug into the glass bulb, heat the underside of the bulb, and inhale the contents (9). In Houston, finely ground glass is mixed with methamphetamine. When inhaled, the mixture scratches the nasal linings, and the drug is absorbed more quickly (7). In the western part of the United States, inhalation predominates in Los Angeles and Phoenix (7, 9). Smoking has increased in San Diego since 1997, replacing inhalation as the preferred route. Injection is the most common use route in Denver, San Francisco, Seattle, and cities in Texas. Inhalation and smoking are the preferred routes in the East and the Midwest (10). Amphetamine in powder form is common to the dance scene. It is sometimes dabbed with a finger onto the gums (this eventually rots the teeth), may be added to alcoholic drinks, or is "bombed" (wrapped into a cigarette paper and swallowed).

\section{Social and cultural contexts influencing ATS abuse}

Public health ATS interventions must reflect an incipient appreciation for the role that social relations, culture, and "meaning making" (explana- 
tory models) have on patterns of ATS-related risk. The association between subculture and ATS abuse is most pronounced among youth. Ethnicity, socioeconomic status, sexual orientation, musical preference, and the high school attended (geographical and environmental determinants) all influence youths' access to and choice of ATSs (8). American street youths, ravers, truck drivers, and motorcycle groups all function in different sociocultural niches, each with its own shared space, identifiable leaders, shared rituals, and adherence to specific codes of behavior. Homosexual or gay communities, for example, can be found in every major city in the United States and in most other major cities of the world. These communities have social, commercial, and political functions. In the United States the communities have gay businesses, bars, athletic centers and gyms, social service centers, phone-sex lines, computer bulletin boards, and churches that are easily accessible and that may serve as locations for ATS acquisition or use (8). It is estimated that 10000 gay men in Los Angeles use methamphetamine regularly, maintaining social networks that facilitate their drug use practices and activities associated with their gay identity (19).

Another important aspect of ATS use in the United States is the abuse of additional drugs, most often alcohol and marijuana. Furr and colleagues (20) reported a strong relationship between daily alcohol intoxication and smoking "ice." According to the NIDA Community Epidemiology Working Group $(7,9,10)$, marijuana is the most common "secondary drug" in San Diego, Chicago, and Houston. Alcohol is the preferred secondary drug in San Francisco and Boston. In Miami, cocaine is the most common secondary drug, and heroin is the most common "tertiary drug." In Chicago and elsewhere, stimulant users may inject a combination of methylphenidate (Ritalin) and heroin. Street outreach workers in the city of New Orleans, Louisiana, report that ecstasy is injected with cocaine and nalbuphine (Nubain), a synthetic narcotic analgesic similar to morphine. Other reports mention frequent mixing of ecstasy with other drugs: LSD ("candy flipping"), psychotropic mushrooms ("flower flipping"), and heroin ("H-bomb"). Some bisexual or gay men use ecstasy in combination with isobutyl nitrate ("poppers") during sexual activity, which increases the heart rate, blood flow, and sexual excitement and also allows for relaxation of the anus without loss of erection.

Among amphetamine users who want to soften the euphoric "high" coming from amphetamine and to allow for sleep, a variety of relaxants are often subsequently employed (21). These can include diazepam, temazepam, and dextromethor- phan hydrobromide (DXM). Many popular OTC cough-control formulas include DXM.

\section{Legal pharmaceutical products and ATS abuse}

In the United States the Food and Drug Administration (FDA) has the primary responsibility for approving and monitoring pharmaceutical products, including legally produced ATSs. The FDA often works in concert with the Justice Department and the DEA to help identify and control the production of illegal ATSs. In 1992 the United States Congress passed the Prescription Drug User Fee Act, which provided additional resources to expedite the FDA's review and approval of new prescription-drug applications (22). Subsequently, the FDA established the Adverse Event Reporting System, a medical watch program, to gather and evaluate spontaneous reports of post-approval problems.

In 1997 the FDA responded to health complications and deaths in the United States that were linked to OTC diet products that contained ATS derivatives (22). Weight loss products and services in the United States make up a market worth some $\$ 33$ billion annually. A rise in obesity rates in the county could lead to an increase in the use of both prescription and OTC diet drugs. The prevalence of obesity in the United States rose from 12\% in 1991 to $17.9 \%$ in 1998 , and obesity is now related to some 300000 deaths a year (23).

\section{Health and psychosocial consequences of ATS abuse}

Chronic ATS abuse can lead to significant social, occupational, and medical impairments (24). The immediate effects of ATS overuse include increases in talkativeness, aggressiveness, breathing rate, heart rate, and blood pressure. ATSs can also produce visual and auditory hallucinations. ATS injecting is believed to be the route of administration associated with most health-related ATS problems and such social harm as violence and crime.

The actions of persons taking ATSs often become compulsive, repetitive, less organized, and the users themselves suspicious and self-conscious (24). Large ATS doses can cause fever and sweating, dry mouth, headache, paleness, blurred vision, dizziness, irregular heartbeat, tremors, loss of coordination, grand mal seizures, and even collapse. Chronic abuse effects include mental illness similar to paranoid schizophrenia, as well as malnutrition, blockage of blood vessels, increased susceptibility 
to illness due to poor diet, and lack of sleep. Death may occur spontaneously due to burst blood vessels in the brain, heart failure, or high fever. However, making direct linkages between these outcomes and ATS use is difficult because of many users' polydrug habit and ATS lifestyles often characterized by reduced nutrition and adverse rest patterns. Babies of mothers who abuse ATS may be born with neurobehavioral abnormalities, low birthweight, cardiac defects, cleft palate, addiction, and withdrawal effects.

Johns Hopkins University scientists report that heavy ecstasy users show a significant decrease in brain cells responsible for reabsorbing serotonin, a messenger chemical involved in mood, appetite, pain perception, sexual drive, and memory (25). Dancing for long periods of time while using ecstasy dehydrates the body and inhibits the body's ability to maintain a normal temperature, with most ecstasy-related deaths resulting from those two effects (26). Because long-term methamphetamine use can produce extreme paranoid delusions (drug-induced psychosis), some methamphetamine addicts are initially seen by mental health or psychiatric units instead of drug treatment programs. A problematic use cycle exists for regular methamphetamine use, according to Rotherm-Borus and colleagues (5):

\begin{abstract}
Methamphetamine use can provide youths with an illusion of excitement and satisfaction in their lives. Initially, it is a means to an end: to get high, to increase sexual potency with others. Eventually, chronic use becomes an end in itself, as waking hours are spent from one run [continuous and accelerated use] to the next and all efforts are geared towards getting more drugs. Instead of sexual potency, sexual dysfunction results; instead of intimacy, further isolation and paranoia occur. The developmental tasks that face all youth are distorted or retarded. Metaphorically and in reality, methamphetamine use is equivalent to going nowhere fast.
\end{abstract}

\section{HIV infection and ATS abuse}

There is a clear connection between ATS abuse and HIV infection, most significantly for users who inject ATS drugs and risk HIV and hepatitis A infections from using shared or tainted needles (27). ATS use also reduces inhibitions, breaking down individuals' psychological and sexual barriers. This was shown, for example, in another study by Rotheram-Borus and colleagues (13). They conducted psychosexual and substance abuse assessment interviews with 337 youths living with HIV in New York City, Los Angeles, Miami, and San Francisco. The researchers found that $38 \%$ of these youths had engaged in amphetamine use in their lifetime, and $21 \%$ of those studied were current users. The youths who had used amphetamines had had more sexual partners and sexual encounters in their lifetime and had engaged in more risky behaviors than those who had never used amphetamines. The amphetamine users were less likely to use condoms during sexual activities, and more likely to inject drugs and share needles. RotheramBorus et al. (13) graphically described the plight of these young people and the significant HIV risk they face:

Initially, new users characterized their experience as a heightening of sexual arousal. Youths on the West Coast frequently had "runs" of the drug. YLH [youths living with HIV] would use amphetamines, especially methamphetamine, for 2 to 4 days, during which time youths reported prolonged periods of sexual arousal, multiple sexual partners, and feelings of euphoria. This "high" was followed by a crash, characterized by a period of depression, feelings of despair, and a lack of sexual desire; such symptoms prompted youths to seek another high and to reinitiate use of amphetamines. However, over time the arousing qualities of the drug decreased; youths, particularly young gay men, reported difficulty in achieving sexual arousal and were uninterested in sex. A constant state of depression resulted among youths [who] were using the drug. Thus, habitual users of methamphetamine reported being unable to have sex without it, and craved the drug when having sex, indicating that there is a cycle of use that will have periods of greater and less risk for HIV transmission.

Other research as well indicates the link between ATS use and HIV infection. A San Francisco study of intravenous drug users (IVDUs) found that the highest HIV seroprevalence $(20 \%)$ occurred among IVDUs whose primary drug was methamphetamine (8). "Speed" users were found to have problems recognizing HIV risks when using drugs and engaging in unprotected sex $(14,28)$. A 1993 NIDA study (8) found that injecting methamphetamine was associated with increased sexual activity. The study also identified "speed" as the "quintessential gay drug because its pharmacological properties contribute to sexual intensity." In a study of gay and bisexual male drug users in Hollywood, researchers found that, in comparison to those not using methamphetamine, methamphetamine users were less likely to use condoms when engaged in high-risk sexual behaviors and were more likely to have used other drugs within the previous 30 days (29). Gulati and colleagues (30) studied two cohorts of methamphetamine users in southern California (one heterosexual, the other gay/bisexual) and 
found a strong connection between methamphetamine use and HIV risk behaviors, especially for heterosexual users who believed they faced little risk of infection. An ethnographic study conducted in San Antonio, Texas, recommended increased riskreduction efforts targeting methamphetamine users. The researchers found that less-sweeping behavioral changes are needed to reduce needle-related HIV risks for "speed" users than for heroin users (31).

\section{Treatment for ATS abuse}

The exact number of people being treated for ATS abuse is difficult to estimate in the United States since there are few facilities that provide ATS-specific treatment. Instead, ATS abusers are referred to treatment facilities that provide services for a wide range of substances, including ATSs.

Methamphetamine users are often overly excitable and extremely resistant to any form of intervention (32). The catalyst for most methamphetamine users to enter treatment is police intervention brought on by the users' aggressive behaviors, fighting, or other bizarre or inappropriate conduct. People arrested under the influence of methamphetamine are some of the most difficult to manage due to high levels of hostility, agitation, and paranoia.

ATS abusers must make dramatic life changes in order to stop using the drugs $(5,14)$. In a study comparing cocaine users and methamphetamine users in San Francisco, Copeland and Sorensen (33) found that the two groups did not differ in treatment compliance, as measured by clinic attendance, drug-free urines, and successful completion of treatment. The researchers recommended that resources should be directed toward addressing "dual diagnosis" issues of multiple physical and mental health problems and toward providing ancillary support services.

ATS treatment in the United States is similar to that for other controlled substances (34). Treatment varies from in-patient 24-hour care to weekly or monthly community-based support groups. Programs often apply such techniques as pharmacotherapy, psychoeducation, behavioral intervention, skills training, and case management. Treatment often focuses on relapse prevention and on the "12-step" approach to social recovery that has been used by such groups as Alcoholics Anonymous and Narcotics Anonymous.

Treatment modalities can vary from "tough love" total cessation models to alternative, holistic harm-reduction behavioral modification approaches (34). Strategies can include efforts to counteract drug effects, improve diet, provide vitamins, and see that users get more sleep or even relocate or make other dramatic lifestyle changes. Harm-reduction approaches attempt to minimize the harm brought about by drug abuse, even if drug abuse cannot be completely halted. One harm-reduction strategy is to combine or replace the drug of choice with drugs that are perceived to be less harmful, such as replacing methamphetamine with marijuana. Behavioral changes may involve balancing the drug "clean-up times" with "mess-up times" and in the process attempting to maximize the "clean-up" periods. New areas of interest in the field of chemical addictions are the biochemistry and neuropathology of addiction. The discovery of opioid receptors has raised the possibility that dependence and tolerance might be explained in terms of changes in these receptors, with the potential for more effective chemical treatment of addiction.

Providing effective treatment for hidden or marginalized populations can be especially hard. In an explanation that may apply to other difficult-toreach groups in the United States and elsewhere, Gorman and his colleagues (8) describe the challenges of serving members of the gay community who use "speed":

Gay and bisexual men who use speed remain largely hidden from mainstream society, from the usual sentinel drug surveillance points, and even from the gay community and their own partners and support systems. Gay and bisexual speed users typically are middle or working class, and are more likely to be Caucasian, Asian, or Latino. They are more likely to live in gentrified neighborhoods in gay-identified geographic communities, and are unlikely to end up in jail unless they are caught drug dealing. They may hold a job for years, in part because they may only use drugs occasionally, and not to the extent that there is interference with job performance. Once they admit they have a problem with speed, they may once again become invisible because there are few if any treatment programs designed for methamphetamine abusers. Many users may be referred to 12-step programs such as NA [Narcotics Anonymous] or to general treatment programs that attempt to address the needs of individuals with a variety of other substance abuse issues and from a variety of cultural and economic backgrounds. A further disincentive is that, as gays, they may be fearful of disclosing their sexual orientation to the treatment program, or they may fear being told it is irrelevant. An additional complication may arise if they have HIV / AIDS since they may feel even more uncomfortable disclosing information about sexual behavior in the context of drug use.

\section{RECOMMENDATIONS}

The recommendations offered below supplement ones generated at the World Health Organization Meeting on Amphetamines, MDMA and 
Other Psychostimulants, which was held in November 1996 in Geneva, Switzerland (35). While many Latin American countries have conducted drug use surveys, little of the resulting information focuses on ATS use. These recommendations are primarily intended for the United States and Canada, but other countries in the Region of the Americas may find them applicable as they also come to face similar problems with ATS abuse.

- To better explain factors that contribute to ATS use, studies must be designed that are age-specific, developmentally appropriate, and culturally sensitive. In addition to focusing on traditionally overstudied marginalized or disenfranchised populations, attention should also be focused on ATS abuse among more affluent groups, given that technological change may promote increased competition and encourage greater ATS abuse among such groups.

- Comparative studies should be conducted specifically on the efficacy of treatment programs employing ATS harm-reduction models versus ones requiring total ATS cessation $(36,37)$.

- An assessment must be made of ATS abuse counseling interventions at such gathering places as schools, concerts, raves, and dance clubs, as well as street corners and other locations where sex workers and ATS users congregate.

- Interventions should be tested where ATS users are assisted in identifying and chronicling their behavioral patterns and activities. Repeated and consistent interventions are needed to raise consciousness of drug use and sexual activities. Motivation for behavioral changes can also come from setting career goals, identifying employment opportunities, and establishing specific plans for the future.

- Longitudinal descriptive field studies are needed to follow ATS users and ascertain the strategies they have used to moderate or discontinue their drug abuse. Attention must be focused on identifying the "turning points" that allow ATS users to change their habits, and on the windows of opportunity for service interventions. Evaluations are also needed of interventions that relocate ATS-addicted people from drug-saturated communities to neighborhoods or sheltered living situations where there are such life alternatives or empowerment initiatives as continuing education and job and technical skills training.

- Additional and innovative uses of the Internet for ATS informational and educational purposes must be explored (35). The Internet offers the opportunity to connect with people who are often unreachable through in-person venues. Evaluation should be conducted on the quality of the information exchanged, its dispersal, and on primary and secondary ATS prevention education targeting middle- and upper-class populations.

Acknowledgements. This paper was contracted for and presented in a longer version at the Second Conference on Amphetamine-Type Stimulants, November 1999, Bangkok, Thailand, World Health Organization (SAB/A2/370/36HQ/99/603315). The author gratefully acknowledges the suggestions of Maristela Monteiro, Evelyn Eisenstein, Marie Teach, and Josue Ferreira.

\section{SINOPSIS \\ Uso y abuso de estimulantes anfetamínicos en Estados Unidos de América}

En los Estados Unidos de América, la popularidad de los compuestos anfetamínicos de consumo legal e ilegal, junto con las prácticas de uso y abuso que con ellos se asocian, han variado a lo largo del tiempo y en distintos lugares. Estos compuestos, que en épocas anteriores evocaban la imagen de obreros blancos de sexo masculino y de personas que seguían regímenes dietéticos de moda para adelgazar, actualmente son consumidos, a menudo en cantidades excesivas, por poblaciones más diversas y numerosas. La magnitud de este uso y abuso de anfetamínicos, que fluctúa según la zona geográfica y el ambiente social y cultural de la localidad, puede cambiar paulatinamente. Los estimulantes anfetamínicos $(E A)$, especialmente la metanfetamina, son ubícuos en los establecimientos nocturnos donde se reúne a bailar la juventud en los Estados Unidos. El uso y abuso diseminados de estas sustancias se observan en poblaciones que consideran menos peligrosos a los EA que a otras sustancias como la cocaína y la heroina. Entre estos grupos de usuarios se encuentran los jóvenes que carecen de representación social, los homosexuales, los bisexuales, los trabajadores del sexo y los estudiantes de bachillerato y universidad. Los EA son relativamente baratos y se fabrican fácilmente en los Estados Unidos. Por consiguiente, es probable que estas drogas sigan siendo codiciadas y disponibles en el mercado ilegal por muchos años más. Dado que el uso y abuso de EA son, en gran parte, prácticas ilegales y clandestinas en los Estados Unidos, resulta imposible enumerar todas las poblaciones que usan EA o que abusan de ellos. Hacen falta estadísticas y sistemas de información más exactos, mejor coordinados y de base poblacional para poder identificar los patrones de uso y abuso de EA y sus tendencias. Esta revisión se apoya en varias fuentes de datos para delinear los aspectos demográficos y culturales del uso y abuso de EA. El trabajo también señala el rumbo que deben seguir los estudios sobre EA en el futuro y los programas de control. 


\section{REFERENCES}

1. United States, Department of Health and Human Services Administration. 1998 National Household Survey on Drug Abuse [Internet site]. Available from: http://www.samhsa.gov. Accessed November 1999.

2. United States, Bureau of Justice Statistics. Drug use and crime. 1999 [Internet site]. United States, BOJS. Available from: http://www.ojp.usdoj.gov/. Accessed November 1999.

3. Bruner $A B$, Fishman M. Adolescents and illicit drug use. JAMA 1998;280(7): 597-598.

4. Austin GA. Research issues: perspectives on the history of psychoactive substance abuse. Rockville, Maryland, United States of America: National Institute on Drug Abuse; 1978.

5. Rotherm-Borus MJ, Luna GC, Marotta T, Kelly H. Going nowhere fast: methamphetamine use and HIV infection. In: Battjes R, Sloboda Z, Grace WC, eds. The context of HIV risk among drug users and their sexual partners. Rockville, Maryland, United States of America: National Institute on Drug Abuse; 1994 p. 155-182.

6. King GR, Ellingwood EH. Amphetamines and other stimulants. In: Lowinson JH, Ruiz P, Millman RB, Langrod JG, eds. Substance abuse: a comprehensive textbook. Baltimore, Maryland, United States of America: Williams and Wilkins; 1992. pp. 247-270.

7. United States, National Institutes of Health, National Institute on Drug Abuse. Epidemiologic trends in drug abuse. Community Epidemiologic Work Group December 1998. Volume I: highlights and executive summary. Bethesda, Maryland, United States of America: National Institutes of Health; 1998

8. Gorman ME, Morgan P, Lambert EY. Qualitative methods in drug abuse and HIV research: qualitative research considerations and other issues in the study of methamphetamine use among men who have sex with other men. In: National Institute on Drug Abuse. Qualitative methods in drug abuse and HIV research. Bethesda, Maryland, United States of America: NIDA; 1995. pp. $156-175$.

9. National Institute on Drug Abuse. Epidemiologic trends in drug abuse. Community Epidemiologic Work Group June 1998. Volume I: highlights and executive summary. Bethesda, Maryland, United States of America: National Institutes of Health; 1998

10. United States, National Institute on Drug Abuse, Community Epidemiologic Work Group. Epidemiologic trends in drug abuse. Volume II: proceedings. Bethesda, Maryland, United States of America: National Institutes of Health; 1998.

11. Narcotics Anonymous. On the spiritual path [Internet site]. Available at: http:/ / www.na.org/html Accessed November 1999.

12. Cocaine Anonymous. Public information fact file [Internet site]. Available at: http://www.ca.org/html Accessed November 1999.

13. Rotheram-Borus MJ, Mann T, Chabon B. Amphetamine use and its correlates among youths living with HIV. AIDS Education and Prevention 1999;11(3): 232-242.

14. Luna GC. Youths living with HIV: selfevident truths. New York: The Haworth Press; 1997.

15. Hyperreal. Frequently asked questions about techno music. What is a rave [Internet site]. Available at: http:// www.hyperreal.org. Accessed November 1999.

16. Luna GC. Working the john/servicing the client: research and outreach on the demand side of male sex work. GMHC/ CASH Newsletter 1994;1:8-9.

17. Holmberg SD. The estimated prevalence and incidence of HIV in 96 large US metropolitan areas. Am J Public Health 1996;86(5):642-654.

18. United States, Department of Justice. Drugs and crime facts [Internet site] Available from: http://www.doj.gov. Accessed November 1999.

19. Eggan F, Reback C, Ditman. Methamphetamine use among gay male drug users: an ethnographic study. Proceedings of the 11th International Conference on AIDS; 1996 July; Vancouver, Canada.

20. Furr CDM, Delva J, Anthony JC. Problems of drug dependence: "ice smoking" and daily episodes of alcohol intoxication: data from a national sample of methamphetamine smokers. In: Harris LS, ed. Problems of drug dependence. Proceedings of the 60th Annual Scientific Meeting, the College on Problems of Drug Dependence. Bethesda, Maryland, United States: National Institute on Drug Abuse; 1998. pp. 109. (Research Monograph 179).

21. ecstasy.org. Other drugs used on the dance scene. Drugs which produce a speedy effect [Internet site]. Available at: http://www.ecstasy.org/info/ dancedrugs.html Accessed November 1999.

22. Friedman MA, Woodcock J, Lumpkin MM, Shuren JE, Hass AE, Thompson LJ. The safety of newly approved medicines: do recent market removals mean there is a problem? JAMA 1999;281(18): 1728-1734.

23. Mokdad AH, Serdula MK, Dietz WH, Bowman BA, Marks JS, Koplan JP. The spread of the obesity epidemic in the United States, 1991-1998. JAMA 1999, 282(16):1519-1522.

24. Life Education Network. Methamphetamine fact sheet [Internet site]. Available at: http://www.lec.org Accessed November 1999.
25. Goode E. Nerve damage to brain linked to heavy use of ecstasy drug. The New York Times 1999 October 18.

26. Dance Safe. Dehydration and overheating [Internet site]. Available at: http:// www.harmreduction.net Accessed November 1999.

27. Hutin YJ, Sabin KM, Hutwagner LC, Schaben L, Shipp GM, Lord DM, et al Multiple modes of hepatitis A virus transmission among methamphetamine users. Am J Epidemiol 2000;152(2): 186-192.

28. Luna GC. Street youth and the AIDS pandemic. AIDS Educ Prev 1992; (4)Suppl:1-13.

29. Reback CJ, Grella CE. HIV risk behaviors of gay and bisexual male methamphetamine users contacted through street outreach. Drug Issues 1999;29(1) $155-166$.

30. Gulati V, Huber A, Reback C, Shoptaw S, Freese T, Rawson R. Problems of drug dependence: high risk behaviors of methamphetamine users. In: Harris LS, ed. Problems of drug dependence. Proceedings of the 60th Annual Scientific Meeting, the College on Problems of Drug Dependence. Bethesda, Maryland, United States: National Institute on Drug Abuse; 1998. p. 111. (Research Monograph 179).

31. Zule WA, Desmond DP. Ethnographic comparison of HIV risk behaviors among heroin and methamphetamine injectors. Drug and Alcohol Abuse 1999; 25(1):1-23.

32. Koch Crime Institute. Fast facts about meth [Internet site]. Available from: http://www.kci.org. Accessed November 1999.

33. Copeland AL, Sorensen JL. Problems of drug dependence: cocaine vs. methamphetamine users: differences in demographics, drug use patterns, and treatment response. In: Harris LS, ed. Problems of drug dependence. Proceedings of the 60th Annual Scientific Meeting, the College on Problems of Drug Dependence. Bethesda, Maryland, United States: National Institute on Drug Abuse; 1998. p. 110. (Research Monograph 179).

34. Yongue JS. Book review of: McCanceKatz EF, Kosten TR, eds. Addiction: new treatments for chemical addictions. JAMA 1999;281(22):2145-2146.

35. World Health Organization. Amphetamine-type stimulants: a report from the WHO Meeting on Amphetamines, MDMA and Other Psychostimulants. Geneva: WHO; 1997.

36. Hawke JM, Jainchill N, De Leon G. Adolescent amphetamine users in treatment: client profiles and treatment outcomes. Psychoactive Drugs 2000;32(1):95-105.

37. Cantwell B, Mcbride AJ. Self detoxification by amphetamine dependent patients: a pilot study. Drug Alcohol Dependence 1998;49(2):157-163. 